\title{
A necessidade das intervenções: Extensão Rural como serviço ou como direito?
}

The need for interventions: Rural Extension as a service or as a right?

La necesidad de intervenciones: Extensión Rurale como un servicio o un derecho?

La nécessité d'interventions: Extension Rurale en tant que service ou comme un droit?

\author{
Davi Augusto Santana de Lelis* \\ France Maria Gontijo Coelho** \\ Marcelo Miná Dias***
}

Recebido em 18/6/2011 revisado e aprovado em 20/12/2011; aceito em 15/1/2012

\begin{abstract}
Resumo: No Brasil a Extensão Rural adquiriu o significado de ação para promoção de mudanças no mundo rural. O sentido do desenvolvimento pretendido pelas políticas públicas que orientam as práticas extensionistas vem sofrendo, recentemente, alterações em sua justificação. A partir da análise das dimensões epistemológica, histórica e político-jurídica, propõe-se, neste artigo, uma Extensão Rural como um veículo de direitos fundamentais.

Palavras-chave: Extensão Rural. Serviço. Direitos Fundamentais.

Abstract: In Brazil, the Rural Extension, has acquired the meaning of actions for promotion of change in rural areas. The development desired by the public policies that guide the Rural Extension practices has been suffering changes in their foundation. From the analysis of epistemological, historical and political-legal dimensions, it is proposed in this paper, an Rural Extension as a vehicle to fundamental rights.

Key words: Rural Extension. Service. Fundamental Right.

Résumé: Au Brésil, la extension rurale, a acquis le sens des actions de promotion du changement dans les zones rurales. Le développement souhaité par les politiques publiques guider l'extension rurale qui a souffert des changements dans les pratiques de leur fondation. De l'analyse des épistémologique, les dimensions historiques et politico-juridique, il est proposé dans ce papier, une vulgarisation en milieu rural comme un véhicule pour les droits fondamentaux.

Mots-clés: Extension Rurale. Service. Droit fondamental.

Resumen: En Brasil, Extensión Agrícola adquirió el significado de la acción para promover el desarrollo en las zonas rurales. La dirección del desarrollo deseado por las políticas públicas que orienten la extensión de las prácticas ha sufrido recientemente, cambios en su justificación. A partir del análisis de las dimensiones epistemológica, histórica y político-jurídica, se propone en este trabajo, una extensión agrícola como un vehículo de los derechos fundamentales. Palabras clave: Extensión Rurale. Servicio. Derechos Fundamentales.
\end{abstract}

\section{Introdução}

Por muitos anos, as práticas de intervenção da chamada Extensão Rural orientaram-se por uma expectativa de mudança social induzida. Nessa concepção de Extensão, a razão das mudanças era quase sempre externa aos contextos locais, e as inovações tecnológicas seriam a mola mestra das transformações.

Nos anos 1980 no Brasil, essa motivação, que justificava as ações dos extensionistas, passou a receber muitas críticas; a maior delas: o outro (aquele afetado pelo trabalho dos extensionistas) não era envolvido como sujeito dos processos de mudança. Esferas decisórias do Estado, grandes empresas e instituições internacionais de pesquisa operavam num contexto sistêmico, no qual os extensionistas eram vistos apenas como engrenagens do processo difusionista. No sentido de ajudar a superação dos impasses práticos da Extensão Rural, com vistas a construção de um novo sentido para a Extensão Rural, este artigo pretende apresentar o que pode ser considerado como fundamentos epistemológicos dessa prática social de intervenção.

\section{Problematizando a questão dos fundamen- tos da Extensão Rural}

Ao longo dos anos, a concepção de intervenção extensionista passou a ser

\footnotetext{
* Mestrando em Extensão Rural no Departamento de Economia Rural - Universidade Federal de Viçosa-MG. E-mail: davilelis@yahoo.com.br

** Professora Adjunta do Departamento de Economia Rural - Universidade Federal de Viçosa. Doutora em Sociologia da Ciência e da Tecnologia pela UnB. E-mail: fmcoelho@ufv.br

*** Professor Adjunto do Departamento de Economia Rural Universidade Federal de Viçosa. Doutor em Ciências Sociais, Agricultura, Desenvolvimento e Sociedade, pelo CPDA/UFRRJ. E-mail: minad@uol.com.br
} 
denominada difusionista, recebendo, principalmente no mundo acadêmico, duras críticas por seus equívocos políticos, científicos e epistemológicos. O reconhecimento do difusionismo entre os extensionistas era de que se fazia a realização eficiente da função que lhes havia sido atribuída - promover mudança induzida por inovações tecnológicas (COELHO, 2005).

Dessa forma, instalava-se um impasse: o que se tornava equívoco para uns (acadêmicos), para outros (técnicos de campo) era acerto eficiente e eficaz, justificado em razão do fim visado - a modificação da base tecnológica da produção. Ainda hoje é possível perceber que, entre essas visões e esses dois campos sociais, afirma-se a incomensurabilidade de paradigmas (KUHN, 1992), ou seja, o diálogo torna-se impossível por não conseguir se basear nas mesmas experiências em virtude da distância da compreensão entre as partes.

O discurso crítico já se tornou lugar comum entre muitos teóricos da extensão, quando proferem análises das práticas difusionistas e de suas justificações. Contudo acredita-se que ainda se faz necessária a busca do entendimento, tanto sobre os objetos com os quais o extensionista trabalha quanto sobre seus significados e implicações socioambientais.

A função de orientação da produção não desaparece das responsabilidades da Extensão Rural. Contudo fica evidente que o desejo dos extensionsitas, de aumento de produção, não acontece no vazio. Isso porque, ao se trabalhar com produção, outras esferas da vida são envolvidas: os limites socioambientais, arranjos político-culturais, universo da interioridade, do espaço psicológico e emocional - tanto dos extensionistas quanto dos agricultores envolvidos por seu trabalho de orientação - compõem um cenário complexo que demanda questionamentos epistemológicos e indagações sobre critérios éticos metodológicos.

Os desafios da Extensão Rural são mais que problemas pessoais de conduta, são problemas de instituição (BOURDIEU, 1996), ou seja, de algo que se instituiu e, como tal, realiza funções de maneira automática e predefinida. A perspectiva política de viabilização da Extensão Rural como um direito, e não só como um serviço, que poderia ou não ser prestado, marca as análises aqui apresentadas. Essa postura implica disposição para a aprendizagem da qual não se furta e para a qual se expõe.

\section{Dimensões da Extensão Rural}

\subsection{Dimensão epistemológica}

De início, o debate traz à tona a natureza e o significado dos conhecimentos que têm orientado as ações extensionistas. $\mathrm{Na}$ interação com seu público, a Extensão tem o conhecimento como objeto de mediação entre o que é e o que poderá ser. Quando se indaga sobre o conhecimento, primeiramente pode-se pensar em questões sobre o que são as coisas que se apresentam diante de nós e, num segundo momento, sobre como se poderia apreendê-las ou compreendê-las.

De forma bastante esclarecedora, Platão (427-347 a.C) tratou do tema do conhecimento quando narrou, no Livro VII de sua obra A República (PLATÃO, 1989). Esse texto é conhecido como Alegoria da Caverna e se apresenta na forma de um diálogo no qual Sócrates propõe questões ao discípulo Glauco. $\mathrm{Na}$ referida alegoria, as pessoas viveriam acorrentadas nas profundezas de uma escura caverna de onde só teriam acesso a imagens projetadas do mundo real, tudo que conhecem são reflexos da realidade, sem poder sequer decidir para que lado olhar, de modo que desconheciam outro mundo e acreditavam ser a caverna o único e verdadeiro plano de existência. Mas eis que surge uma pessoa que se liberta dos grilhões e sai da caverna em busca do mundo exterior, e contempla a verdade real. Maravilhado com a descoberta, esse indivíduo retorna à caverna para dizer que o que eles veem são apenas projeções da realidade, mas os acorrentados não acreditam nos relatos e acabam por matar o liberto. Para o pensamento platônico, essa pessoa que contempla a realidade seria o filósofo, que se liberta dos grilhões por meio do conhecimento atingindo assim o mundo real (PLATÃO, 1989, p. 52).

Essa narrativa pode ser interpretada de muitas formas, mas, neste artigo, ela tem a função de exercício de reflexão sobre a natureza social do conhecimento e da verdade. Mesmo falando a partir do mito, permite-se perceber uma íntima relação existente entre 
o contexto social, a forma de produção e de divulgação com suas implicações sobre a valoração e a reprodução do saber. A linguagem e o método, os fins, o sentido e o significado das coisas vistas e ditas são possíveis, da forma como se apresentam, com interações numa dada sociedade.

Ao percorrer a história do pensamento sobre o conhecimento no mundo ocidental cristão, outras referências despontam como esclarecedoras para serem postas neste debate. O conhecimento foi concebido no período medieval, como efeito da revelação e, por isso, seria oriundo do universo divino, espiritual, cabendo à Igreja sua gestão na terra. Essa visão do conhecimento como próprio dessa instituição e da autorização divina sofre uma ruptura no século XVII, quando uma nova origem do conhecimento surge: a científica. Nessa visão, o conhecimento é posto como uma força libertadora, e a ciência aparece como possibilidade de rompimento com o sobrenatural e com o mundo mágico.

Sob essa nova perspectiva, Bacon (15611626) propunha uma produção da ciência organizada e institucionalizada, e Descartes (1596-1650), um conhecimento fruto da dúvida. Assim, ao longo dos séculos que se seguiram, a ciência passou a receber uma aura de sacralidade que lhe autoriza os discursos que anuncia e os produtos que gera no mundo contemporâneo. Esse poderio científico do futuro foi aberto por esses filósofos a partir de dois métodos.

Nesse sentido, Descartes alertava que só fugiria dos fantasmas da caverna, que hoje podem ser traduzidos como fantasmas do poder no mundo cientificado, aquele que seguisse as quatro regras básicas para a geração do conhecimento: a) duvidar é existir: o que não significa duvidar de tudo, mas sim observar motivado pela dúvida, isso seria o motor dos questionamentos do indivíduo; b) dividir as dificuldades facilita a compreensão do todo, devendo o estudo ser iniciado pelas partes mais simples; c) ao se analisar as proposições mais simples é possível compreender as mais complexas; d) aplicar o empirismo na busca de evidências, construindo assim o conhecimento pelo teste de hipóteses.

Já Bacon, por sua vez, apontava o conhecimento como uma força libertadora via empirismo, exclusivamente. Vislumbrando um conflito instalado, o pensador em questão, acreditava que a institucionalização seria a solução, uma vez que a hierarquia, a ocupação distinta de cargos, bem como as instituições e normas seriam capazes de produzir novos inventos e recursos para a felicidade humana. Esses novos inventos gerados seriam então colocados a serviço do homem, que modificaria a realidade (BACON, 1983).

Embora pareçam distintas, as duas formas de pensar a ciência possuem completude. Descartes queria formar pessoas com uma ciência solipsista, enquanto Bacon aspirava formar instituições para uma ciência utilitária. Descartes objetivava formar mentes, Bacon controlar e modificar a natureza. Descartes almejava uma ciência de forma isolada, uma vez que o foco era o indivíduo, já Bacon pretendia uma ciência coletiva. Ambos concordavam que o trabalho seria realizado por conhecimento, sendo que para Descartes a razão representaria a liberdade, e para Bacon, o trabalho seria fundamentado pela própria sociedade.

De uma forma ou de outra, com suas completudes e diferenças, as duas vertentes de pensamento definem o início do período moderno de produção de conhecimento, que no caso foi adjetivado como científico. Esse processo completou-se com o surgimento dos iluministas (século XVIII até início do XIX). A forma de pensar a ciência, desse momento, se apropria das ideias anteriores, além do que, outras áreas do conhecimento surgem e se especializam em campos de saber distintos como a definição de objetos distintos. Todas as esferas do conhecimento são recortadas em pedaços e racionalizadas sob a justificação de busca da emancipação social, do bem-estar geral, da liberdade, da igualdade e da fraternidade da sociedade.

A partir de meados do século XIX, uma nova concepção para a ciência se coloca: o positivismo. Desse modo, desponta o progresso técnico, quando começa a prevalecer a técnica em detrimento do pensamento esclarecedor; separando a ciência da técnica, privilegiase, de forma distinta, a inspiração inicial de Francis Bacon. Ao privilegiar os correlatos técnicos da ciência, o desenvolvimento filosófico e a reflexão crítica relativa à ciência, esta é mitigada. Essa forma de produção do saber, bem como o império da produção econômica 
capitalista industrial, configura um pano de fundo que permite melhor entender a dinâmica da sociedade que se afirmava e sua relação predatória com o ambiente.

Com esse cenário, é possível afirmar que a produção do conhecimento na modernidade está vinculada à técnica, que por sua vez permite a produção industrial em um caminho dominado por instituições e interesses econômicos capitalistas, deixando, muitas vezes, à margem, marcas sociais e limites ambientais. Abaliza esse pensamento Edgar Morin, que afirma com razão a vinculação explicitada. Nas palavras do autor:

A técnica aparece como um momento nesse circuito em que a ciência produz a técnica, que produz a indústria, que produz a sociedade industrial; circuito em que há, efetivamente, um retorno, e cada termo retroage sobre o precedente, isto é a indústria retroage sobre a técnica e a orienta, e a técnica sobre a ciência, orientando-a também. (MORIN, 2005, p. 107).

Ou seja, temos um ciclo autopoiético em que a técnica não está isolada da ciência, que, por sua vez, não está isolada da indústria. E no sistema posto, temos a exploração do homem pelo homem em uma forma muito distante da imaginada pelo projeto iluminista, uma vez que:

[...] o desenvolvimento da técnica não provoca somente processos de emancipação, mas também novos processos de manipulação do homem pelo homem ou dos indivíduos humanos pelas entidades sociais. [...] A sujeição significa que o sujeito sujeitado sempre julga que trabalha para seus próprios fins, desconhecendo que, na realidade, trabalha para os fins daquele que o sujeita. Assim, efetivamente, o carneiro-chefe do rebanho julga que continua a comandar seu rebanho, quando, na realidade, obedece ao pastor e, finalmente à lógica do matadouro. (MORIN, 2005, p. 109).

Entretanto acredita-se que essa lógica não impera totalmente em todos os espaços sociais. Para essa crença, é preciso, como bem disse Pinto (2008), focar a capacidade que os homens têm de se maravilhar (ou se escandalizar) diante do mundo. Por meio de seu intelecto, os homens são capazes de resolver problemas impostos pela dura realidade.

Portanto, hoje, há uma dinâmica que se poderia denominar como pós-moderna, que não se opõe nem nega a modernidade.
Nesse contexto intenso, reina: a) triunfo da igualdade repressiva; b) hierarquia e coerção; c) expressão individual; d) transformação do homem em objeto; e) opressão tecnológica; f) substituição das formas místicas de pensar; g) impotência do trabalhador. Enquanto pelo iluminismo teve-se uma dinâmica completamente diferente, que apenas ilustra o conjunto de mudanças que acabou por configurar tal realidade pois era preciso produzir: a) o triunfo da igualdade; b) homens livres; c) ciência transformando os mitos; d) a razão visando ao novo. A história e o diferente ajudam, assim, a melhor entender os porquês e o como estamos.

\subsection{Dimensão histórica da ciência, da} técnica e da tecnologia para agricultura

Ao pesquisar o processo histórico de apropriação da agricultura por formas científicas de produção de conhecimentos, Coelho (2005) identificou tipos diferentes de métodos científicos e de resultados. No Brasil, originalmente, a forma científica de tratamento dos conhecimentos para agricultura, restringiu-se ao registro sistemático, tanto de observações sobre processos naturais quanto dos resultados da manipulação realizada pelos homens. Esses registros é que criaram as condições necessárias para maior controle dos manejos e dos resultados produtivos. Essa fase, denominada pela autora como fase da ciência experiência, vai do final do século XIX até o final dos anos 1930.

Num segundo momento, em razão da importação de conhecimentos mais complexos (como a genética e o instrumental estatístico), as experiências com plantas e animais transformaram-se em experimentos sob controle. Assim, a ciência para agricultura, tornase capaz de produzir segredos. Esta seria a fase da ciência experimento que, a partir do final dos anos 1930, vai se instalar e expandir para todas as subáreas do conhecimento científico agrícola.

No processo de institucionalização da pesquisa experimental pura sob controle, foi possível perceber que as destrezas necessárias ao desenvolvimento e à criação de novas práticas de produção de conhecimentos sobre plantas ou de animais sofisticam-se. A análise desse processo destacou a ideia e a importância 
da técnica como disposições incorporadas. Essa evidência permitiu remeter ao conceito de habitus, como definia Bourdieu (1989), ou seja, disposições incorporadas que contemplam tanto o instituído (o que já era conhecido) quanto o instituinte (aquilo que permite condições para novas invenções). Por isso, considerando o processo de cientificação dos conhecimentos para agricultura, propõe-se um entendimento da técnica como habitus.

A ciência experiência resultou em ciência e técnica; e a ciência experimento resultou no que foi denominado por Coelho (2005), como tecnologia, que retoma a teoria da mercadoria de Karl Marx, pois, ao produzirem-se segredos, os experimentos criam a razão do fetiche de seus resultados o qual, como um produto, ocorrerá apenas pelo mercado.

Numa perspectiva crítica diante da importância da tecnologia na sociedade atual, Pinto (2008) esclarece que o termo tecnologia comportaria quatro acepções: a) no sentido etimológico, tecnologia seria apenas o estudo do logos da técnica; b) numa forma mais simplória, o significado de tecnologia seria intercambiável com a própria técnica. Essa equivalência, contudo, diz o autor, gera confusão e "perigosos enganos no julgamento de problemas sociológicos e filosóficos suscitados pelo intento de compreender a tecnologia" (PINTO, 2008, p. 219-220); c) em sentido histórico seria "o conjunto de todas as técnicas de que dispõe uma determinada sociedade, em qualquer fase histórica de seu desenvolvimento" (PINTO, 2008, p. 220). E por fim; d) tecnologia como ideologização da técnica. Sobre esta última acepção é que o autor se debruça, pois ela comporta uma ideia de sociedade e de desenvolvimento.

Assim, como síntese dos dois autores, pode-se entender que tecnologia comporta mais que objetos que potencializam processos de produção. Tecnologia envolve valores e objetos que predispõem formas de sociedade e de relações sociais e econômicas, que podem ser, ou não, as melhores ou as mais adequadas à diversidade de contextos socioambientais.

Ao se perceber a diferença entre técnica (como habitus) e tecnologia (como ideologia e mercadoria), é possível assumir uma postura crítica diante das potencialidades anunciadas pelo industrialismo e pelo progresso tecnológico. O fetiche da mercadoria enche os olhos de quem a vê, na medida em que cria expectativas de que satisfará desejos. Esse é o efeito e a natureza da tecnologia mercadoria: anunciar possibilidades e potencializar realizações. A tecnologia tem então essa capacidade de projetar abstratamente e realizar concretamente (PINTO, 2008).

Enquanto mercadoria, a tecnologia é propriedade de empresas que, necessariamente, devem gerar lucros ao capital. No caso do espaço agrário, a tecnologia normalmente cria uma rede de dependência dos agricultores com um mercado de insumos. Ao pensar em tecnologia, não se pode desconsiderar essa sua dupla natureza, de potencialização da produção e de dominação, que surge no contexto das relações capitalistas.

O discurso modernizante encontrou eco nas expectativas extensionistas de promoção de mudanças tecnológicas, que podem ser entendidas como uma concepção ideológica estratégica e eficaz para o projeto político de desenvolvimento da época. Por isso não se pode dizer, de forma indistinta, que o uso dessas tecnologias torna a sociedade mais agradável, mais produtiva ou mais rentável. Mas é possível afirmar que as mudanças tecnológicas industriais tornaram os processos produtivos, no espaço agrário, mais rentáveis para o capital. Assim, a distinção entre técnica e tecnologia faz toda a diferença na orientação da prática extensionista: a primeira foca no compromisso com a formação de habilidades e de competências, a segunda, na persuasão para seu consumo.

\subsection{Propósitos e equívocos da extensão de conhecimentos}

Cabe agora esclarecer como se dá a influência dessa estrutura de produção de conhecimento sobre a extensão rural. Uma análise da formação da extensão rural no Brasil é o ponto de partida. Contudo, desde já, é bom que se diga:

O trabalho de assistência técnica da Extensão Rural no Brasil era um projeto educativo para o capital (industrial e financeiro). [...] Por isso, a idéia de transferir certos traços de 'cultura' e recursos de uma condição social considerada mais avançada (a sociedade urbana e industrial) para outros espaços sociais considerados atrasados (o espaço agrário) foi, e para alguns ainda é, 
um equivoco baseado na prepotência camuflada de 'boa vontade' ou voluntarismo autoritário. (COELHO, 2005, p. 71).

Desse modo, tem-se um modelo clássico de extensão rural, estabelecido desde o século XIX nos Estados Unidos (EUA) pautado na expectativa da difusão da tecnologia. Assim, inicialmente nos EUA, por volta de 1870, tem-se um abandono da produção agrícola para o consumo próprio para privilegiar a produção de mercado. Tal mudança produtiva fez com que os fazendeiros americanos formassem associações para a solução de seus problemas, bem como criassem feiras agrícolas para apresentação dos resultados conquistados no campo. Essa iniciativa gerou um círculo de mais pesquisa agrícola para aumentar a produtividade, solucionar os novos problemas que por ventura aparecessem pelo caminho para, novamente, exibir melhores resultados nas feiras (FONSECA, 1985, p. 38). Note-se que tal sistema surgiu num espaço social, com apoio de instituições de pesquisa, não sendo imposto pelo Estado, mas sim aproveitado por este. Desse modo, o pensamento aplicado era de que a maior produção econômica elevaria, por consequência, a qualidade de vida dos chamados fazendeiros.

Nessa senda, foi estabelecido no Brasil um modelo de educação no campo que, de maneira informal, pudesse promover a produção voltada para o mercado. Em contínuo avanço na trilha do desenvolvimento econômico industrial no final da década de 1940, os serviços da extensão rural foram institucionalizados. É nesse cenário que Nelson Rockefeller propôs um programa de desenvolvimento rural, aplicado, em princípio, no estado de Minas Gerais (FONSECA, 1985). Tal escolha se deu pelo cenário ofertado por Minas Gerais naquele momento. Uma vez bem sucedido nas terras mineiras, o programa poderia se espalhar pelo restante do país. Para tornar o sucesso palpável, nos idos de 1950 diversos técnicos estadunidenses foram para as universidades rurais de Minas Gerais, dando cursos de economia doméstica e de métodos extensivos de agricultura (EMBAIXADA DOS ESTADOS UNIDOS apud FONSECA, 1985 , p. 86-87). Conforme o script, entre 1948 e 1967, diversas associações nos moldes supramencionados surgiram em diversos estados brasileiros e também no Distrito Federal na época, Guanabara, RJ, comprovando assim o aparente sucesso do plano extensionista fundado em teor econômico com vistas ao aumento da produtividade.

O homem do campo brasileiro, entendido como iletrado, doente, xucro e despreparado para a produção, havia sido seduzido pela ótica de mercado. Assim, atribuía-se que ele desejava tornar-se letrado, saudável, motorizado, empresário. Isso porque a sedução é feita pelo próprio objeto da sedução. As facilidades, o conforto, o lucro prometido pelo sistema imposto fazem, por si só, as vezes de sedutor (PARRET, 1991, p. 21). Mesmo porque:

[...] a ação extensionista envolve, qualquer que seja o setor em que se realiza, a necessidade que sentem aqueles que a fazem, de ir até a 'outra parte do mundo', considerada inferior, para, à sua maneira, 'normalizá-la' . Para fazê-la mais ou menos semelhante a seu mundo. (FREIRE, 1983, p. 13).

Desse modo, a extensão rural simplesmente troca uma forma de conhecimento, o cotidiano, por outro, o tecnológico. Entretanto o conhecer não é destinado a objetos, mas sim a sujeitos, o que demanda o querer saber, a curiosidade sobre o mundo. Por isso, segundo Freire (1983), aquele que simplesmente recebe não tem espaço, motivação autônoma ou sentido para querer aprender; cabe apenas consumir, acatar ou reproduzir o que lhe é ofertado.

Tem-se então um sistema de extensão feito pelo e para o capital de forma que os fatores sociais e ambientais são pouco relevantes e, diversas vezes, são vistos como empecilhos ao desenvolvimento econômico.

\subsection{Dimensão político-jurídica}

Nesta parte, pretende-se discutir o sentido da Extensão Rural enquanto organização e instituição social. Para tanto, o conceito de desenvolvimento coloca-se como um fundamento importante na argumentação. Inicialmente pode-se dizer que o termo desenvolvimento está repleto de significados, que, por sua vez, estão ligados a diversas teorias criadas para entender o fenômeno. Favareto (2007) trabalha na distinção de três significados: desenvolvimento econômico, social e ambiental: 
a) Desenvolvimento Econômico: essa concepção tem como implicação a expectativa de que o desenvolvimento se fará por meio da difusão, adoção e aplicação da técnica e da tecnologia (FAVARETO, 2007, p. 51). Essa visão, também denominada monista, orientou o Estado brasileiro entre os anos 1950 e 1990, tornando restritas as possibilidades de construção de uma vida social mais equitativa. Essa concepção se instituiu ao largo desse período, mesmo quando o Estado interveio de forma a garantir políticas mais distributivas; mesmo que essas políticas recebessem sua legitimação por meio de eleições gerais ou tivesse suas bases sociais em sindicatos autônomos ou em partidos dos trabalhadores. Contudo o desenvolvimento econômico continua como um desafio estatal, pois:

Ele deve intervir no sistema econômico com o objetivo de proteger o crescimento capitalista, minorar as crises e proteger simultaneamente a capacidade de competição internacional das empresas e ofertas de trabalho - a fim de que advenham crescimentos que possam ser repartidos sem desencorajar os investimentos privados. (HABERMAS, 1987, p. 107).

b) Desenvolvimento Social: nessa concepção, caberia ao Estado promover a igualdade entre os homens por meio do bem-estar social. Quanto mais próximos da igualdade estiverem os homens, mais justo será o Estado por eles formado, maior a capacidade de distribuição de direitos e deveres, e maiores as condições de redistribuição de renda, com existência e oportunidades iguais que seriam dadas aos indivíduos de forma distinta (RALWS, 2002).

Essa concepção remete a Chauí (1999), que esclarece as condições para essa redistribuição social. Para que a economia capitalista realizasse o Bem-Estar foi preciso que "o Estado nela interviesse como regulador e como parceiro, o que foi feito pela criação do fundo público" (CHAUí, 1999, p. 213). Em torno desse fundo público é que o jogo de forças políticas que constituem o Estado é realizado. Assim:

Em suma, o Estado do Bem-Estar introduziu a república entendida estruturalmente como gestão dos fundos públicos, os quais se tomam pré-condição da acumulação e da reprodução do capital (e da formação da taxa de lucro) e da reprodução da força de trabalho por meio das despesas sociais. (CHAUÍ, 1999, p. 213).

Na concepção de desenvolvimento como bem-estar social, a noção de democracia coloca-se apenas como um regime de lei e de ordem. Como diz Chauí, essa democracia pode ser lida como restrita, pois não está fundada na noção de direito, na medida em que, efetivamente, garante privilégios (que são sempre particulares e não podem universalizar-se num direito) do capital e visa suprir carências (que são sempre específicas e particulares, por não conseguirem ultrapassar a especificidade rumo a sua universalização como um direito). Assim, somente no sentido de uma ação criadora de direitos universalizáveis é que se poderia pensar nas condições para uma democracia plena. Na primeira forma, enquanto serviços, o modelo estruturante seria o de uma organização social; mas, para a garantia de direitos, há que se pensar num Estado constituído de Instituições Sociais autônomas, que significam:

[...] uma ação social, uma prática social fundada no reconhecimento público de sua legitimidade e de suas atribuições, num princípio de diferenciação que lhe confere autonomia perante outras instituições sociais, estruturada por ordenamentos, regras, normas e valores de reconhecimento e legitimidade internos a ela. (CHAUÍ, 1999, p. 217).

Nessa segunda concepção de desenvolvimento, tendo em vista essa visão crítica do Welfare State e de instituição social de Chauí, inspira-se que a Extensão Rural poderia ser concebida como uma instituição social, ou seja, uma ação social de intervenção do Estado. Contudo, historicamente, ela tem-se apresentado como uma organização prestadora de serviços em detrimento de operacionalizar direitos.

c) Desenvolvimento Ambiental: a terceira concepção de desenvolvimento exige também uma política intervencionista, que objetive primariamente a conservação das condições ambientais. Para tanto, o ambiente passa a ser visto como um bem comum a todos, pertencente aos habitantes atuais e às futuras gerações. A saber, a Constituição da República Federativa do Brasil, em consonância com a Política 
Ambiental Nacional, assim trata o tema:

Art. 225 - Todos têm direito ao meio ambiente ecologicamente equilibrado, bem de uso comum do povo, e essencial à sadia qualidade de vida, impondo-se ao Poder Público e à coletividade o dever de defendêlo e preservá-lo para as presentes e futuras gerações. (BRASIL, 1988).

Não é demais afirmar que o tratamento dado ao ambiente por essa concepção de desenvolvimento reveste-se de certa homogeneidade (BONETI, 2007, p. 21) ao pensar sua preservação como um todo, sendo uma posição refratária do ideal de fraternidade no seio social.

As potencialidades ou limites ambientais exigem que se conceba a natureza a partir não só de sua constituição biológica. Natureza é aquilo que é definido, social e culturalmente, como natureza. Nesse contexto de atribuições de significados e de definição de usos legítimos do ambiente, seguramente, a Extensão Rural assume papel de destaque. A liberdade de exploração econômica, cujas justificativas são respaldadas em limites postos por um genérico bem-estar socioambiental, desafia, cotidianamente, a ação dos extensionistas.

Na medida em que a ciência ainda é tímida na construção de propostas conservacionistas, muitas vezes o extensionista se vê só, entre regulamentos e normas que não dão conta da diversidade e da espacialidade nas quais se está inserido como agente de mudança. Contudo há que se reconhecer que o sentido depredatório tem marcado muito mais as propostas existentes e carece-se de inovações aplicáveis.

\section{Uma síntese: caminhos possíveis}

Em 1981, Lawrence Busch já havia apontado algumas alternativas ao sistema produtivo na agricultura, como: a) priorizar a produção de alimentos para consumo interno, ao invés da produção para exportação; b) promover a pesquisa agrícola que priorize a estrutura familiar agrícola; c) tratar a propriedade rural como um sistema tal qual o farming system research preconiza; d) adotar o exemplo chinês em que as questões agrícolas são tratadas como questão de saúde pública e de indústria (BUSCH, 1981).

Alguns autores, ao perceberem problemas na efetividade das práticas da Extensão
Rural, propunham uma adequação tecnológica ou a adequação de um genérico homem do campo às propostas levadas pela Extensão, como foi o caso de Rodrigues (1987).

Acredita-se que uma presentificação do projeto iluminista de libertação do homem em convívio com seu ambiente poderia ser pensada. Isso porque, se o "iluminismo é um tendência trans-epocal, que cruza transversalmente a história" (ROUANET, 1989, p. 35), pode-se esperar que:

Equipado de um novo modelo de razão e um novo conceito de crítica, dispondo de um acervo de valores próprios, que não coincidem inteiramente com os de nenhuma outra corrente, e enraizado num solo social que o salva de todo o idealismo, o novo Iluminismo estará pronto para prosseguir a tarefa que a Ilustração não pôde concluir. Hoje como ontem, é preciso combater todas as instâncias que promovem a infantilização do homem, impedindo a realização do ideal maior da Ilustração, [...]. Mas o trabalho de secularização ficou incompleto, e devemos continuar combatendo as religiões profanas - as da nação, da raça, da classe, do Estado [e por que não dizer, da imposição tecnológica que desconsidera a necessidade de reprodução das condições sócio-ambientais para a produção agrícola] que engendram um fanatismo tão obscurantista quanto o que Voltaire quis combater no século XVIII. (ROUANET, 1989, p. 35).

A organização dessa mudança, que é não só paradigmática, mas também pragmática, depende da atuação reflexiva dos extensionistas. O fazer com o outro, no caso o agricultor, difere da proposta do fazer para o outro na medida em que procura romper com a postura etnocêntrica.

Em síntese, como intitulado por Roling (1996), esse paradigma interativo, como nova proposta que atribui nova função para Extensão Rural, pode ser caracterizado da seguinte forma: a) construtivista; $b$ ) a verdade adquire perspectivas múltiplas e diversas; c) o tratamento entre os atores envolvidos se estabelece em um processo interativo e participativo; d) as metas são múltiplas e frequentemente se confrontam; e) o sistema permite uma ação coletiva; f) a política resulta das interações na realidade; g) a ciência tem papel ativo na construção social da realidade; $h$ ) a ciência é um híbrido entre as ciências naturais e as ciências sociais; i) a extensão rural facilita a 
aprendizagem e estimula os métodos participativos.

Mas, para operacionalizar esses princípios, a extensão rural interativa necessita assumir novos papéis que não podem ser eventuais, mas sim, estruturantes do mundo social, produtivo e ambiental. Essas mudanças não se dão ao acaso ou na eventualidade, para tanto, acredita-se ser pré-condição para esse caminho admitir-se a possibilidade de questionamento sobre as concepções e conteúdos dos tipos de conhecimentos com os quais se lida. Além disso, tornam-se indispensáveis os questionamentos quanto às formas metodológicas operacionalizadas no cotidiano do extensionista e, uma conceituação sociológica clara para melhor denominação do público envolvido em suas ações.

Todas as alternativas até então apresentadas ou vivenciadas, desde a origem da Extensão Rural, colocam-na como um serviço. Entretanto, ao se pensar nas questões postas por Chauí (1999), pode-se propor que a Extensão Rural, como política pública, atualmente orientada pela preocupação agroecológica e pela participação cidadã dos agricultores, evidencia que ela faz (ou deveria fazer) algo mais que assistência ou mero serviço. Ao refletir sobre os desafios cognitivos, produtivos, político-jurídicos e socioambientais, chega-se à proposta de que a Extensão Rural pública, modificada em sua justificativa e em seus fundamentos, pode ser concebida como um veículo de realização de direitos fundamentais.

\section{Proposição: Extensão Rural, instituição pública e direito}

Conforme orienta a doutrina jurídica moderna (MENDES, 2008), os direitos fundamentais podem ser analisados por gerações, considerando o contexto nos quais surgiram:

a) Primeira Geração: Direitos civis e políticos que realçam o princípio da liberdade. Surgem institucionalmente a partir da Magna Carta inglesa de 1215. Tais direitos tinham caráter negativo, ou seja, não exigiam nenhuma atuação por parte do Estado, apenas definiam que ele não interferisse no exercício da liberdade dos indivíduos, desde que ele se encontrasse dentro dos limites da legalidade. Estes direitos se prestaram a

[...] fundamentar a estruturação de mecanismos políticos e institucionais destinados a assegurar a preservação da autonomia do indivíduo em face do Estado. (DALLARI, 2009, p. 197).

Tais direitos reverbam a dimensão econômica da Extensão Rural e podem ser classificados como:

[...] direitos aos quais o Estado não impeça ou sirva de obstáculo a determinadas ações do titular do direito; [...] por direitos sobre os quais o Estado não afete determinadas propriedades ou situações do titular do Direito; [...] por direitos que o Estado não elimine determinadas posições jurídicas do titular. (ALEXY, 1993, p. 189).

b) Segunda Geração: Direitos econômicos, sociais e culturais que realçam o princípio da igualdade. Segundo Dallari (2009, p. 198), estes surgem da timidez na implementação dos preceitos dos direitos da primeira geração. Esses direitos englobam os direitos relacionados com o trabalho, ao seguro social, à subsistência, ao amparo à doença, à velhice, à educação entre outros. Tais direitos surgiram com a dupla revolução do séc. XVIII, a industrial e a política, mais especificamente a francesa. Eles têm caráter positivo, ou seja, exigem que o Estado atue para promoção da igualdade e consequente bem-estar social.

Tais direitos podem exigir uma atuação fática do Estado, como o auxílio ao agricultor familiar por meio da Extensão Rural, ou com uma atuação normativa, como por exemplo, a normatização do crédito para a agricultura familiar, como consta na Lei 11.326 de 24 de julho de 2006. Em suma, o titular de um direito fundamental deve ter uma ação estatal que seja indispensável para a proteção do seu âmbito de liberdade assegurado por disposições jurídico-fundamentais (ALEXY, 1993, p. 240). E, de fato, uma decorrência dos direitos de segunda geração é, segundo Dallari (2009, p. 199), o fortalecimento do papel do Estado na proteção e promoção desses direitos.

c) Terceira Geração: Direitos atribuídos a qualquer formação social de modo que realçam o princípio da fraternidade. Surgem no contexto político e social "da segunda metade do século XX" (DALLARI, 
2009, p. 203). Esses direitos englobam o direito a um meio ambiente equilibrado, à qualidade de vida, à paz e outros direitos difusos e coletivos. Por fim, tais direitos guardam relação com a terceira dimensão apontada por Favaretto (2007), qual seja, a dimensão ambiental do desenvolvimento, que toca a Extensão Rural no quesito de proteção ambiental, diversidade genética, uso de produtos químicos entre outros temas correlatos. De fato,

[...] o direito a um meio ambiente equilibrado, que assegure condições adequadas a uma vida digna, insere-se na terceira geração dos direitos humanos [fundamentais], que considera o ser humano como integrante de uma coletividade e identifica os direitos de solidariedade. (DALLARI, 2009, p. 203).

Não é demais apontar que essa distinção em gerações é meramente didática, portanto,

[...] falar em sucessão de gerações não significa dizer que os direitos previstos num momento tenham sido suplantados por aqueles surgidos em um instante seguinte. (MENDES, 2008, p. 234).

Ainda quanto a esses direitos, Cunha Júnior (2006) aponta que, segundo a Constituição de 1988, as normas definidoras de direitos (e garantias) fundamentais têm aplicação imediata, o que significa afirmar que, em princípio, essas normas têm eficácia plena, não sendo dependentes de qualquer interposição do legislador para terem a efetividade ou eficácia social.

Quando se pensa em uma Extensão Rural que se compromete como o acesso do agricultor à liberdade, à igualdade ou à fraternidade - tríade que, desde a Revolução Francesa, encontra guarida nas constituições modernas em capítulos destinados aos direitos e garantias fundamentais dos cidadãos - pode-se buscar definir melhor que direito é esse do qual aqui se fala. Os direitos podem ser assim entendidos como "aqueles direitos que pertencem ao mesmo fundamento do Estado, e que, por isto, são reconhecidos na constituição" (SCHMITT apud ALEXY, 1993, p. 63).

Assim, acredita-se que as mudanças sociais contemporâneas não podem permitir que se viva sem os preceitos que garantam a liberdade, a igualdade e a fraternidade. A liberdade, por sua vez, revela-se em questões concretas, como no direito de uma produção econômica e sustentabilidade das condições ambientais dessa produção. A igualdade aparece na garantia de condições sociais de existência que respeita padrões de vida coletivos e seus valores. E a fraternidade se expressa na garantia de condições de respeito aos aspectos ambientais.

Desse modo, os direitos sobre os quais a Extensão Rural firma seu porto são, de longa data, devidos aos agricultores, podendo ser vistos como direitos fundamentais garantidos pela Constituição da República. Não se trata apenas de garantir acesso à tecnologia ou distribuição de novas técnicas de produção e comercialização, mas também, e quiçá, primordialmente, fazer valer direitos da mais alta monta, como o direito a orientações que extrapolam, em suas consequências, o espaço das unidades produtivas.

Essa mudança de perspectiva envolve também um aspecto de nomenclatura. O Estado não carece de extensionistas difusores de tecnologias, pois disso se encarregam as empresas produtoras e vendedoras de insumos agroindustriais, mas sim de agentes de desenvolvimento. Nesse contexto, o papel do agente de desenvolvimento é, portanto, desafiar os agricultores, para que estes busquem a significação do conteúdo temático diante do qual se encontram.

Propõe-se assim, ainda que de forma tímida, a inversão da ótica posta. Para tanto, o agricultor deixa de ser um objeto que recebe as novas tecnologias, e passa a ser ator e exige seus direitos. A extensão rural deixa de privilegiar a mera transferência de tecnologia, para privilegiar a execução de projetos e programas que elevem a condição inicial do projeto iluminista para, enfim, promover a igualdade, a emancipação social, e o bemestar da coletividade sob os pilares de direitos fundamentais.

\section{À guisa de conclusões}

Com base nas premissas, fundamentos e argumentos expostos ao longo do presente trabalho, pontuam-se as principais conclusões deste estudo.

A Extensão Rural, historicamente, atua como um serviço para o meio rural. 
Nessa perspectiva, seria de competência dos extensionistas promover o deslocamento da técnica desenvolvida por institutos, como universidades, empresas públicas ou privadas, para o público alvo dessas ações. Entretanto, quando não há problematização ou debate acerca de seus objetos e da configuração do próprio meio rural, a ação extensionista, nesses moldes, não leva em conta o conhecimento do agricultor. Isso acontece mesmo que alternativas a esse modelo já tenham sido apontadas, como o Farming System Research ou o Farming First.

Abandonar o padrão clássico difusionista de atuação se faz necessário. Para tanto, entende-se que, diante de uma concepção mais crítica do desenvolvimento rural, a Extensão Rural poderá atuar sobre outros pilares que têm em vista liberdade econômica, igualdade social e fraternidade ambiental. Tais pilares representam a tríade constitucional dos direitos fundamentais que permitem elevar a Extensão Rural a um novo patamar: a de garantidora de direitos fundamentais.

Ao se considerar a Extensão Rural como um veículo para direitos fundamentais, a lógica tecnocrata se perde. Visto que a função primeira do Estado é garantir direitos para os cidadãos, (incluindo-se os agricultores familiares), o amplo acesso ao desenvolvimento exige uma nova perspectiva para a praxis do extensionista. Para tanto, seus fundamentos carecem ser ancorados em outras bases, inclusive pode ser estratégico alterar sua própria denominação identitária de extensionista para agente do desenvolvimento.

Ao se admitir a Extensão Rural como um veículo para direitos fundamentais, constrói-se uma estrutura que permite a participação dos agricultores nas questões que lhes são mais caras. Ao se garantir aos agricultores o papel de destaque nessa instituição pública, viabilizam-se as condições para que estes exijam, pelos meios legais, as faltas e ausências estatais que por ventura surjam na busca contínua pelo desenvolvimento. Esses focos externos e orientações internas são pré-condições para a dignidade do trabalho desses agentes de desenvolvimento na promoção do justo e merecido desenvolvimento do meio rural.

\section{Referências}

ALEXY, Robert. Teoria de los derechos fundamentales. Madrid: Centro de Estudos Constitucionales, 1993.

BACON, Francis. Nova Atlântida. 2. ed. São Paulo: Abril Cultural, 1983. (Coleção os Pensadores).

BRASIL. Constituição da República Federativa do Brasil. 05 de outubro de 1988. Disponível em: <http:// www.planalto.gov.br/ccivil_03/constituicao/ constitui\%C3\%A7ao.htm>. Acesso em: 30 jan. 2011.

BONETI, Lindomar Wessler. Políticas públicas por dentro. 2. ed. Ijuí: Ed. Ijuí, 2007.

BOURDIEU, Pierre. Espaço social e gênese das classes. A gênese dos conceitos de habitus e de campo. In: . Poder simbólico. Rio de Janeiro: Bertrand Brasil, 1989. p. 59-73.

Edusp, 1996.

Economia das trocas linguísticas. São Paulo:

BUSCH, Lawrence; SACHS, Carolyn. The agricultural sciences and the modern world system. In: BUSCH, L. (Ed.). Science and agricultural development. New Jersey: Allanheld, Osmum, 1981.

CHAUÍ, Marilena. A universidade em ruínas. In: TRINDADE, Hélio (Org.). Universidade em ruínas: na república dos professores. 3. ed. Petrópolis, RJ: Vozes/Rio Grande do Sul: CIPEDES, 1999.

COELHO, France Maria Gontijo. A arte das orientações técnicas em campo. Viçosa: UFV, 2005.

DALLARI, Pedro. Desenvolvimento sustentável em favor da Justiça Social no Brasil. In: PÁDUA, José Augusto (Org). Desenvolvimento, justiça e meio ambiente. Belo Horizonte: UFMG, 2009.

DENT, J. B.; MEGREGOR, M. J. Rural and farming systems analysis european perspectives. Willingford: Cab. International, 1994.

DESCARTES, René. Discurso do Método. Disponível em: <http://br.egroups.com/group/acropolis/>. Acesso em: 17 abr. 2010.

FAVARETO, Arilson. Paradigmas do Desenvolvimento Rural em Questão. São Paulo: Editora FAPESP/Iglu, 2007.

FONSECA, Maria Tereza Louza. Extensão rural: uma educação para o capital. São Paulo: Edições Loyola, 1985.

FREIRE, Paulo. Extensão ou comunicação. Rio de Janeiro: Paz e Terra, 1983.

HABERMAS, Jurgen. A nova intransparência: a crise do estado de bem-estar social e o esgotamento das energias utópicas. Novos Estudos CEBRAP, São Paulo, n. 18, p. 103-114, setembro, 1987.

JÚNIOR, Dirley da cunha. A efetividade dos direitos fundamentais sociais e a reserva do possível. In: CAMARGO, Marcelo Novelino (Org.). Direito Constitucional: leituras complementares. Salvador: JusPODIVM, 2006.

KUHN, Thomas Samuel. A estrutura das revoluções científicas. Tradução de Beatriz Vianna Boeira e Nelson Boeira. 3. ed. São Paulo: Perspectiva, 1992. 257 p. (série Debates - Ciência)

MENDES, Gilmar Ferreira et al. Curso de direito constitucional. 2. ed. rev. e atual. São Paulo: Saraiva, 2008. 
MORIN, Edgar. Epistemologia da tecnologia. O desafio da complexidade. In: de Janeiro: Bertrand Brasil, 2005.

MUNIZ, J. N. A extensão rural em tempos de mudanças. Informe Agropecuário, Belo Horizonte, v. 20, n. 199, p. 56-61, jul./ago. 1999.

PARRET, Herman. Os argumentos do sedutor. Revista Comunicação e Linguagens, Lisboa, n. 14, p. 9-22, Dez. 1991.

PINTO, Álvaro Vieira. O conceito de tecnologia. Rio de Janeiro: Contraponto, 2008. V. 1.

PLATÃO. A república. Brasília: UnB/Ática, 1989. Livro VII.

RAWLS, John. Uma teoria da justiça. 2. ed. São Paulo: Martins Fontes, 2002.
RODRIGUES, Cyro Mascarenhas. A pesquisa agropecuária no período do pós-guerra. Cadernos de Difusão de Tecnologia, São Paulo, v. 4, n. 3, p. 205-254, set./dez. 1987.

ROLING, N. Toward an interactive agricultural science. European Journal os Agricultural Education and Extension, v. 2, n. 4, p. 35-48, 1996.

ROUANET, S. P. As razões do Ilumisno. São Paulo: Companhia das Letras, 1989.

SCHMITT, Carl. Verfassungsrechtliche auftaaze aus den Jahren. 1924-1954. Materialien zu einer Verfassungslehre. 2. ed. Berlim, 1973. In: ALEXY, Robert. Teoria de los Derechos Fundamentales. Madrid: Centro de Estudos Constitucionales, 1993.

SILVA, José Afonso da Silva. Curso de Direito Constitucional positivo. São Paulo: Malheiros, 1992. 